\title{
Novel combustion synthesis of carbon foamaluminum fluoride nanocomposite materials
}

DOI:

10.1016/j.matdes.2018.02.021

\section{Document Version}

Accepted author manuscript

Link to publication record in Manchester Research Explorer

\section{Citation for published version (APA):}

Matthews, A., Kostoglou, N., Gunduz, I., Isik, T., Ortalan, V., Constantinides, G., Kontos, A. G., Steriotis, T., Ryzhkov, V., Bousser, E., Doumanidis, C., Mitterer, C., \& Rebholz, C. (2018). Novel combustion synthesis of carbon foamaluminum fluoride nanocomposite materials. Materials \& Design, 144, 222-228.

https://doi.org/10.1016/j.matdes.2018.02.021

Published in:

Materials \& Design

\section{Citing this paper}

Please note that where the full-text provided on Manchester Research Explorer is the Author Accepted Manuscript or Proof version this may differ from the final Published version. If citing, it is advised that you check and use the publisher's definitive version.

\section{General rights}

Copyright and moral rights for the publications made accessible in the Research Explorer are retained by the authors and/or other copyright owners and it is a condition of accessing publications that users recognise and abide by the legal requirements associated with these rights.

\section{Takedown policy}

If you believe that this document breaches copyright please refer to the University of Manchester's Takedown Procedures [http://man.ac.uk/04Y6Bo] or contact uml.scholarlycommunications@manchester.ac.uk providing relevant details, so we can investigate your claim.

\section{OPEN ACCESS}




\section{Highlights}

- A carbon/ $/ \mathrm{AlF}_{3}$ nanocomposite was produced by a novel combustion synthesis route.

- The combustion product is composed of cubic $\alpha-\mathrm{AlF}_{3}$ nanoparticles dispersed in a porous carbon foam matrix.

- The combustion method represents a fast and scalable alternative to wet chemical procedures. 


\section{Novel combustion synthesis of carbon foam-aluminum fluoride nanocomposite materials}

Nikolaos Kostoglou ${ }^{\mathrm{a}, \mathrm{b}}$, I. Emre Gunduz ${ }^{\mathrm{c} *}$, Tugba Isik ${ }^{\mathrm{c}}$, Volkan Ortalan ${ }^{\mathrm{d}}$, Georgios Constantinides ${ }^{\mathrm{e}}$, Athanassios G. Kontos ${ }^{\mathrm{f}}$, Theodore Steriotis ${ }^{\mathrm{f}}$, Vladislav Ryzhkov ${ }^{\mathrm{g}}$, Etienne Bousser ${ }^{\mathrm{h}}$, Allan Matthews ${ }^{\mathrm{h}}$, Charalabos Doumanidis ${ }^{\mathrm{i}, \mathrm{j}}$, Christian Mitterer ${ }^{\mathrm{a}}$, Claus Rebholz $^{\mathrm{b}, \mathrm{h}}$

${ }^{a}$ Department of Physical Metallurgy and Materials Testing, Montanuniversität Leoben, 8700 Leoben, Austria

${ }^{\mathrm{b}}$ Department of Mechanical and Manufacturing Engineering, University of Cyprus, 1678 Nicosia, Cyprus

${ }^{\mathrm{c}}$ School of Mechanical Engineering, Purdue University, West Lafayette, IN 47907, USA

${ }^{\mathrm{d}}$ School of Materials Engineering, Purdue University, West Lafayette, IN 47907, USA

${ }^{\mathrm{e}}$ Research Unit for Nanostructured Materials Systems, Department of Mechanical Engineering and Materials Science and Engineering, Cyprus University of Technology, 3036 Lemesos, Cyprus

${ }^{\mathrm{f}}$ Institute of Nanoscience and Nanotechnology, National Center for Scientific Research Demokritos, Agia Paraskevi Attikis, 15341 Athens, Greece

${ }^{\mathrm{g}}$ Nanotube Production Department, Fibrtec Incorporation, Atlanta, TZ 75551, USA

${ }^{\mathrm{h}}$ School of Materials, University of Manchester, ICAM-Pariser Building, Manchester M13BB, UK

${ }^{\mathrm{i}}$ Department of Mechanical Engineering, Khalifa University of Science and Technology, P.O. Box 127788, Abu Dhabi, UAE

${ }^{\mathrm{j}}$ Office of the Provost, Nazarbayev University, 010000 Astana, Kazakhstan 
* Corresponding author. Tel.: +4368110554221; Email address:

nikolaos.kostoglou@ stud.unileoben.ac.at (Nikolaos Kostoglou); Tel.: (765)494-0066; Fax:

(765)494-0530; Email address: igunduz@ @urdue.edu (Emre Gunduz)

\begin{abstract}
The facile, rapid and bulk production of composite materials consisting of carbon nanostructures doped with metal-based compounds has been a significant challenge for various research areas where such types of materials can be applied, including catalysis, energy storage and water purification. In this work, a carbon foam-aluminum fluoride composite $\left(\mathrm{C}-\mathrm{AlF}_{3}\right)$ was developed by adopting a combustion synthesis approach, which is an attractive alternative to wet chemical methods usually employed for such purposes. The flame ignition and combustion of a solid-state mixture comprising a fluoropolymer and nano-sized Al powder leads to the formation of a porous carbon foam network doped with dispersed cubic-like $\mathrm{AlF}_{3}$ nanoparticles (100 to $500 \mathrm{~nm}$ in size), as observed by high-resolution microscopy methods. Selective area electron diffraction and X-ray diffraction studies revealed a rhombohedral $\alpha-\mathrm{AlF}_{3}$ crystal structure for these embedded particles, while micro-Raman spectroscopy indicated typical carbonaceous features for the foamy matrix. The $\mathrm{C}-\mathrm{AlF}_{3}$ composite also showed a combination of micro-, meso- and macro-porous characteristics (i.e. pore sizes in the nanometer scale) based on the analysis of $\mathrm{N}_{2}$ sorption data collected at $77 \mathrm{~K}$. The findings of this study provide useful insights for further research on carbon-based nanocomposite materials prepared via direct combustion synthesis routes.
\end{abstract}

Keywords: nanocomposite; porous material; carbon foam; aluminum fluoride; combustion synthesis 


\section{Introduction}

Significant research efforts have been devoted over the last decade towards the facile, rapid, high-yield and low-cost development of composites consisting of carbon nanostructures (e.g. activated carbons, nanotubes, graphene etc.) and other compounds, such as metallic- and/or inorganic-based nano-sized particles, clusters or thin films [1-5]. Such composite materials may exhibit a combination of properties favorable for rapidly expanding and materials-oriented research areas, including gas sensing [6], carbon dioxide conversion [7], hydrogen storage [8], electrochemical energy storage [9], water treatment [10] and capacitive desalination [11]. Their promising performance in such applications is attributed not only to the individual characteristics of the host carbonaceous support and the hosted/embedded substance, but also to the potential synergy between the two. Even though a large number of carbonbased composite structures has been presented in the literature, only limited attention has been given to the development of carbon-metal fluoride systems. Metal/inorganic fluorides such as aluminum fluoride $\left(\mathrm{AlF}_{3}\right)$ have been widely used as catalysts for the production of olefins in petrochemical processes [12,13], as additives for the production of aluminum in electrolytic cells $[14,15]$, as well as ingredients for the production of fluoride glasses for mid-infrared optical applications [16,17]. In recent years, nano-sized $\mathrm{AlF}_{3}$ has also attracted significant attention in the technology of rechargeable lithiumion batteries by acting as a useful additive to enhance their electrochemical performance [18-21]. The most common laboratory-scale method of preparing $\mathrm{AlF}_{3}$ involves the wet chemical treatment of $\mathrm{Al}$ or Al-based substances with hydrofluoric acid (HF) [22]. On the other hand, amorphous carbon foams with tuned porosity, specific areas, pore volumes and surface chemistries are frequently produced using a variety of procedures, such as physical or chemical blowing of carbon precursors, template carbonization, compression of exfoliated graphite, and assembly of graphene nanosheets [23-26]. Such porous carbonaceous structures act as effective matrices/substrates for the deposition of catalytically 
active nanoparticles, which are, in most cases, introduced onto the carbon surface in a subsequent stage (upon synthesis), combining wet chemical and thermal reduction processes [1].

In this work, a carbon foam-aluminum fluoride composite material (denoted hereafter as $\mathrm{C}-\mathrm{AlF}_{3}$ ) was developed on the basis of a rapid, reproducible, scalable, and wet-free synthesis method that involves the combustion of a commercially available fluoropolymer (THV) mixed with nano-sized aluminum (nAl) powder. The use of $\mathrm{nAl}$ promotes significantly the reaction rates due to the larger available specific area of the nano-sized particles compared to their micro-scale counterparts [27]. Solid mixtures of Al and fluoropolymers can react rapidly and form $\mathrm{AlF}_{3}$ while releasing large amounts of heat upon combustion [28]. Characteristically, the fluorination reaction of $\mathrm{Al}$ that leads to the formation of $\mathrm{AlF}_{3}$ can release up to $\sim 56 \mathrm{~kJ}$ per $\mathrm{g}$ of $\mathrm{Al}$ powder, while other Al-based compounds, such as alumina $\left(\mathrm{Al}_{2} \mathrm{O}_{3}\right)$, exhibit about half of this energy release (up to $\sim 31 \mathrm{~kJ}$ ) [29]. Recent work has been reported on the production of such nanostructured solid mixtures, composed of $\mathrm{Al}$ and PFTE (polytetrafluoroethylene), for energetic applications by ball milling procedures, but the product species and morphology have not been investigated [30]. Surface morphology, elemental composition, structure and porosity of the reaction product were investigated by scanning electron microscopy (SEM) combined with energy dispersive Xray spectroscopy (EDX), transmission electron microscopy (TEM) combined with selected area electron diffraction (SAED), X-ray diffraction (XRD), micro-Raman spectroscopy, as well as $\mathrm{N}_{2}$ adsorption and desorption measurements at $77 \mathrm{~K}$. The synthesis approach of fabricating composite nanostructures through combustion of solid-state reactants offers an attractive alternative to complicated, multi-step and time-consuming physical and/or chemical synthesis procedures.

\section{Materials and methods}




\subsection{Combustion synthesis method}

The $\mathrm{C}-\mathrm{AlF}_{3}$ composite was directly produced using $\mathrm{THV}\left(3 \mathrm{M}^{\mathrm{TM}}\right.$ Dyneon ${ }^{\mathrm{TM}} 221 \mathrm{AZ}$ fluoropolymer) and $\mathrm{nAl}$ powder (Novacentrix; $80 \mathrm{~nm}$ average particle diameter; $76 \%$ active content) as precursors, followed by ignition and self-propagating combustion of their mixture. THV has the empirical formula $\mathrm{C}_{2.29} \mathrm{~F}_{4.33} \mathrm{H}_{0.25}$, comprises of three different monomers, i.e. tetrafluoroethylene $\left(\mathrm{C}_{2} \mathrm{~F}_{4}\right)$, hexafluoropropylene $\left(\mathrm{C}_{3} \mathrm{~F}_{6}\right)$ and vinilidene fluoride $\left(\mathrm{C}_{2} \mathrm{H}_{2} \mathrm{~F}_{2}\right)$, and possesses a melting point of $115^{\circ} \mathrm{C}$. Molten THV is very viscous and it has a very low melt flow index. In a typical synthesis procedure, 900 mg of THV was placed in a stainless steel bowl and was heated to $160{ }^{\circ} \mathrm{C}$ using a hot plate. In a following step, $100 \mathrm{mg}$ of $\mathrm{nAl}$ was poured on the molten THV. The mixture was then pressed and folded in half repeatedly by hand for 30 min to make sure the particles were well distributed within the viscous THV matrix. The THV-nAl mixture (total mass of $1 \mathrm{~g}$ ) was solidified upon cooling down to room temperature. Small pieces were cut using a blade and then ignited using a butane torch within a fume hood. Once ignited, the mixture started burning at an average rate of $0.2 \mathrm{~mm} / \mathrm{s}$ and the combustion reaction formed a "foam snake". The final product was collected as a black powder and was studied without further processing (i.e. in the as-prepared condition). Fig. 1 shows digital photos of the solidified THV-nAl mixture before and during combustion.

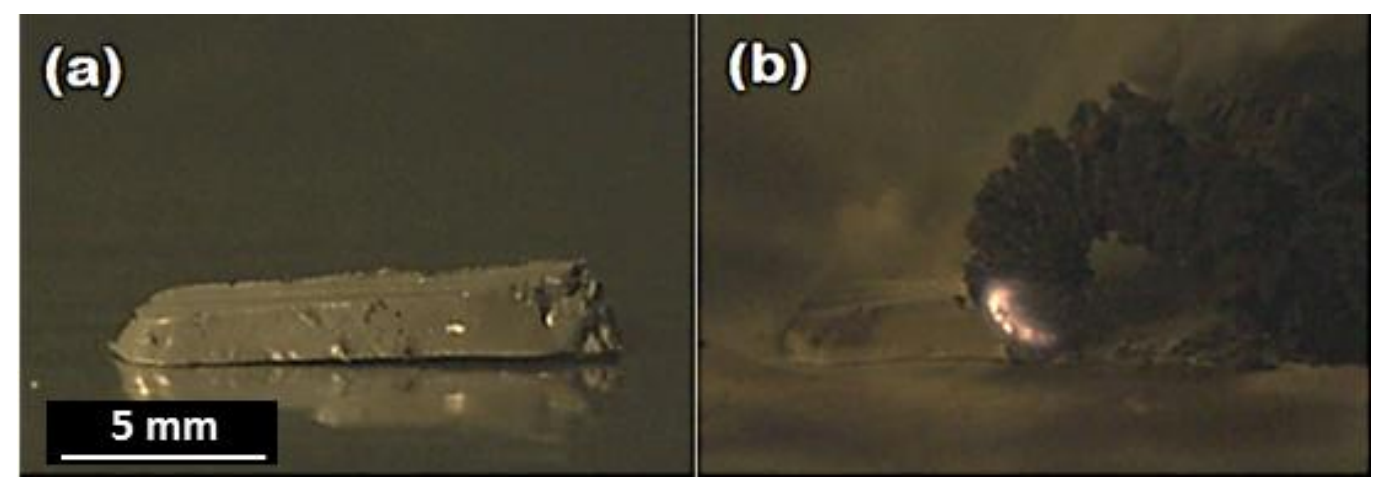

Fig. 1 - Digital photos showing (a) the mixed THV-nAl solid sample and (b) the formation of the foam product phase during combustion. 


\subsection{Characterization methods}

SEM images at different magnifications were collected using an FEI Quanta 200 microscope using acceleration voltages between 10 and $20 \mathrm{kV}$ and a working distance of $10 \mathrm{~mm}$. The studied sample was sputter-coated with a gold ( $\mathrm{Au}$ ) layer (estimated thickness of 1-2 $\mathrm{nm}$ ) under an argon atmosphere using a Quorum Technologies SC7640 sputter coater to inhibit charging effects during imaging as well as to support the powder onto the sample holder and avoid particle movements. The same sample was also micro-analyzed using an EDVAC Genesis X-ray analysis probe mounted on the SEM instrument using an acceleration voltage of $20 \mathrm{kV}$ to obtain EDX spectral patterns for various sites of its surface.

High-resolution TEM images were collected using an FEI Titan Environmental microscope operated at $300 \mathrm{kV}$ acceleration voltage. The powder sample was diluted in acetone at $1 \mathrm{wt} . \%$ and mixed via ultrasonication until a homogeneous solution was obtained. TEM copper grids were then dipped into the asprepared solution to form a thin film of $\sim 200 \mathrm{~nm}$. SAED patterns were also collected for the same sample and subsequently analyzed to determine the produced crystalline phases. The aperture size was $200 \mu \mathrm{m}$ and the probed area had a radius of $\sim 2 \mu \mathrm{m}$. The results of this analysis were also verified with diffraction pattern simulations performed in the CrysTBox software [31]. Fractal dimension analysis of SEM and TEM images was carried out via box-counting algorithms on grey-scale rasters using the MATLAB software for image processing [32].

X-ray diffractograms were recorded by a Bruker-AXS D8 Advance diffractometer equipped with $\mathrm{Cu} \mathrm{K} \alpha$ radiation (wavelength $\lambda \sim 1.54 \AA$ ) using voltage and current values of $40 \mathrm{kV}$ and $40 \mathrm{~mA}$, respectively. These measurements were performed in Bragg-Brentano geometry using a continuous scan speed mode between the diffraction angles (20) of 10 and $60^{\circ}$, a $0.01^{\circ}$ step width and a $0.5 \%$ min scan speed. 
Micro-Raman spectroscopic investigations were performed by excitation with a solid-state laser emitting at $514.5 \mathrm{~nm}$ on an inVia Reflex Renishaw spectrometer. The laser beam was focused on spots of $4.5 \mu \mathrm{m}$ in diameter with an objective lens having $\times 20$ magnification and 0.14 numerical aperture. The Raman signal averages on sample areas of $20 \mu \mathrm{m}^{2}$ with a power density of $0.02 \mathrm{~mW} / \mu \mathrm{m}^{2}$ that was determined as a safety threshold against laser heating and thermally induced spectral changes. In order to achieve a high-quality quantitative analysis, the recorded Raman spectrum was peak fitted with mixed LorenzianGaussian components.

The $\mathrm{N}_{2}$ adsorption/desorption isotherm was recorded at $77 \mathrm{~K}$ by a Quantachrome Autosorb-1 MP volumetric gas sorption analyzer using a liquid $\mathrm{N}_{2}$ bath and ultra-pure $(99.999 \%) \mathrm{N}_{2}$ gas. Prior to these measurements, a sample of $\sim 50 \mathrm{mg}$ was degassed under vacuum $\left(10^{-6} \mathrm{mbar}\right)$ at $250{ }^{\circ} \mathrm{C}$ overnight with the aim of removing any physisorbed species remaining on the material's surface. The total specific area was calculated using the multi-point Brunauer-Emmet-Teller (BET) method in the relative pressure region $\left(\mathrm{P} / \mathrm{P}_{0}\right)$ between 0.05 and 0.12 of the $\mathrm{N}_{2}$ adsorption data, following the BET consistency criteria of the International Standard Organization (ISO 9277:2010) [33]. The micropore specific area and volume values (i.e. for pore widths below $2 \mathrm{~nm}$ ) were estimated using the Carbon Black statistical thickness equation (also known as t-plot method) [34]. A detailed pore size distribution (PSD) analysis was carried out by applying the Quenched Solid Density Functional Theory (QSDFT) kernel for slit/cylinder-like shape pores in the recorded $\mathrm{N}_{2}$ desorption data [35]. 


\section{Results and discussion}

\subsection{Surface morphology and elemental composition}

Fig. 2 shows SEM images in a sequence of increasing magnification revealing the hierarchical structure of the as-prepared $\mathrm{CF}-\mathrm{AlF}_{3}$ nanocomposite. Fig. 2a evidences a foam-like morphology generated from the interconnection of carbon-based particles linked in a way that forms an open network with a series of micron- and nano-scale spaces and voids (Figs. 2b and 2c). Characteristic cubic- and/or cuboid-like shaped particles can be clearly observed at higher magnifications in many locations within the foamy structure of the powder material (Figs. 2d-f). These dispersed particles possess sharp edges and exhibit a characteristic size in the range of 100 to $550 \mathrm{~nm}$, with an average particle size of $\sim 240 \mathrm{~nm}$ as estimated from a statistical analysis of different high-magnification SEM images (Fig. S1).

The aforementioned morphology was also investigated in more detail using high-resolution TEM analysis (Fig. 2g and 2h). Specifically, Fig. 2g shows clearly two of these particles having cuboid-like shapes with side lengths between $\sim 250$ and $\sim 550 \mathrm{~nm}$, similar to the values previously mentioned in the SEM analysis, while Fig. 2h displays the amorphous carbonaceous foam which appears to exhibit a porous shell-like structure. The morphology of the starting THV-nAl mixture prior combustion is also shown in Fig. S2 for comparison. The equivalent TEM image highlights agglomerates of spherical nAl particles, with sub-micrometer dimensions, dispersed within the THV polymer matrix. The individual nAl particles exhibit diameters below $100 \mathrm{~nm}$, in good agreement with the technical specifications of the $\mathrm{nAl}$ powder presented in section 2.1 (i.e. $80 \mathrm{~nm}$ average size). 

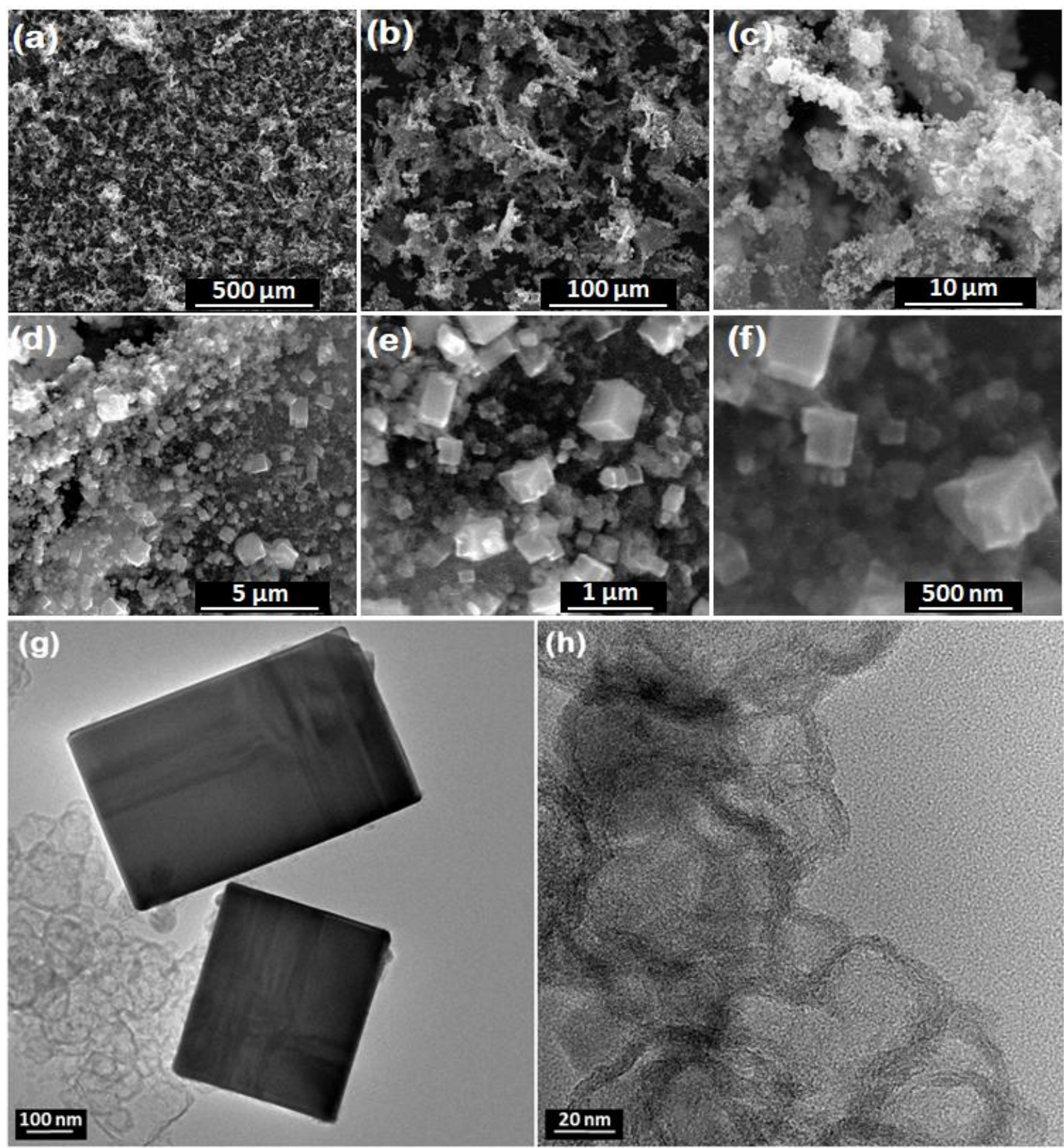

Fig. 2 - SEM images of the as-prepared $\mathrm{C}-\mathrm{AlF}_{3}$ composite at different magnifications showing (a), (b), (c) the hierarchical details of the open carbon foam structure and (d), (e), (f) the embedded $\alpha-\mathrm{AlF}_{3}$ nanoparticles and high-resolution TEM images of the $(\mathrm{g}) \alpha-\mathrm{AlF}_{3}$ crystals and (h) amorphous carbonaceous foam. 
Table 1 illustrates the fractal dimension parameters $(f)$ for the SEM and TEM images of Fig. 2, through capacity, information, correlation and probability-based image processing algorithms [36]. By moving to lower dimensions, the $f$ values show clearly a continuous finite, bimodal self-similarity, transitioning from a Brownian branching network for the amorphous carbon foam to an Apollonian globular pack of $\alpha-\mathrm{AlF}_{3}$ crystal nanoparticles, thus indicating multiple types of surface area contributors within the composite structure [37].

Table 1 - Fractal dimension parameters $(f)$ of the SEM and TEM images shown in Fig. 2.

\begin{tabular}{cccccccccc}
\hline & $\begin{array}{c}\text { Fig. 2a } \\
\mathbf{5 0 0} \boldsymbol{\mu m}\end{array}$ & $\begin{array}{c}\text { Fig. 2b } \\
\mathbf{1 0 0} \boldsymbol{\mu m}\end{array}$ & $\begin{array}{c}\text { Fig. 2c } \\
\mathbf{1 0} \boldsymbol{\mu m}\end{array}$ & $\begin{array}{c}\text { Fig. 2d } \\
\mathbf{5} \boldsymbol{\mu m}\end{array}$ & $\begin{array}{c}\text { Fig. 2e } \\
\mathbf{1} \boldsymbol{\mu m}\end{array}$ & $\begin{array}{c}\text { Fig. 2f } \\
\mathbf{5 0 0} \mathbf{~ n m}\end{array}$ & $\begin{array}{c}\text { Fig. 2g } \\
\mathbf{1 0 0} \mathbf{~ n m}\end{array}$ & $\begin{array}{c}\text { Fig. 2h } \\
\mathbf{2 0} \mathbf{~ n m}\end{array}$ & Average \\
\hline Capacity & 2.71 & 2.63 & 2.51 & 2.57 & 2.50 & 2.30 & 2.27 & 2.59 & 2.51 \\
Information & 2.64 & 2.52 & 2.39 & 2.47 & 2.38 & 2.13 & 2.15 & 2.58 & 2.41 \\
Correlation & 2.36 & 2.26 & 2.16 & 2.22 & 2.18 & 2.02 & 2.11 & 2.57 & 2.23 \\
Probability & 2.47 & 2.37 & 2.39 & 2.36 & 2.26 & 2.23 & 2.29 & 2.66 & 2.38 \\
\hline
\end{tabular}

Fig. S3 presents a typical EDX spectrum of the as-prepared $\mathrm{CF}-\mathrm{AlF}_{3}$ material. The elements of carbon $(\mathrm{C})$, oxygen $(\mathrm{O})$, fluorine $(\mathrm{F})$, aluminum $(\mathrm{Al})$, and gold $(\mathrm{Au})$ were detected. $\mathrm{C}, \mathrm{O}, \mathrm{F}$ and $\mathrm{Al}$ are part of the constituent phases of the initial mixing precursors (THV and $\mathrm{nAl}$ ), whereas Au was used as the sputter-coating material prior to the SEM/EDX studies. The atomic percentages of these elements (excluding $\mathrm{Au}$ ) are shown in the inset of Fig. S3 with the errors of the EDX quantification lying between 1 and 2 at.\%. The dominant elements $\mathrm{C}$ and $\mathrm{F}$ (57.4 and 28.5 at.\%, respectively) are complemented with lower proportions of $\mathrm{Al}$ and $\mathrm{O}$ (7.7 and 6.4 at.\%, respectively). EDX elemental mapping of the surface is shown in Fig. S4, indicating that the locations where the cubic- and/or cuboid-like particles exist (i.e. regions 1 to 4 ) contain primarily $\mathrm{Al}$ and $\mathrm{F}$. This suggests that these embedded nanoparticles are most probably $\mathrm{AlF}_{3}$ crystals that were formed upon combustion of the THV-nAl mixture, whereas the calculated elemental fractions of $\mathrm{Al}$ and $\mathrm{F}$ also indicate that the latter is dominantly present within these crystals, nearly corresponding to the stoichiometric ratio of $\mathrm{AlF}_{3}(1: 3)$. 


\subsection{Combustion reaction and $\mathrm{AlF}_{3}$ formation mechanism}

The adiabatic reaction temperature and final product phases upon combustion were calculated using the NASA chemical equilibrium analysis (CEA) code at the composition of $10 \mathrm{wt} . \% \mathrm{nAl}$ with an active content of $74 \mathrm{wt} . \%$ (the rest $26 \mathrm{wt} . \%$ being the oxide layer). Based on these findings, we are able to propose mechanisms related to the combustion reaction and $\mathrm{AlF}_{3}$ formation, as described below. Once the solid THV-nAl mixture is ignited, the exothermic reactions between the decomposition products of THV, including HF, and $\mathrm{nAl}$ result in a combustion wave that rapidly travels across the sample to form a "foam snake" containing $\mathrm{AlF}_{3}$ and carbon. Other calculated products are primarily gaseous $\mathrm{CF}_{4}$ and $\mathrm{CO}$ and a small amount of HF. Although gaseous HF is hazardous, it can be recovered and re-used in synthesis of fluoropolymers in an industrial setting. For example, TFE (monomer for Teflon) is made using mixtures with $\mathrm{HF}$ reacted at temperatures up to $900{ }^{\circ} \mathrm{C}$. The adiabatic reaction temperature is calculated at $1552 \mathrm{~K}$, which is slightly above the sublimation temperature of $\mathrm{AlF}_{3}$ (i.e. $1550 \mathrm{~K}$ ). Therefore, once the $\mathrm{AlF}_{3}$ sublimates, it reaches the cooler air and then condenses into the cube-like crystals of $\mathrm{AlF}_{3}$ within the carbon matrix. The yield of the foamy product was also calculated at $\sim 25 \%$ by considering the mass change of the solidified THV-nAl mixture upon combustion (i.e. reduced by $\sim 75 \%)$.

\subsection{Structural features}

The SAED analysis of a single $\mathrm{AlF}_{3}$ particle accompanied with a simulated diffraction pattern are both presented in Fig. 3. The interplanar spacings (d) calculated from the SAED patterns (Fig. 3a) were compared to literature to identify the reaction product phase. The analysis indicated that the cubicand/or cuboid-like particles observed by the SEM and TEM are related to rhombohedral $\alpha-\mathrm{AlF}_{3}$ crystals, which is thermodynamically the most stable polymorph out of the five well known $\mathrm{AlF}_{3}$ phases [38]. In addition, the measured $d$ values matched well with the ones of five crystallographic 
planes, namely $(\overline{1} 1 \overline{2}),\left(\begin{array}{lll}1 & 0 & 4\end{array}\right),(\overline{2} 2 \overline{4}),(\overline{2} 3 \overline{2})$, and $(\overline{3} 4 \overline{4})$, shown in the simulated diffraction pattern (Fig. 3b) provided by the CrysTBox software [31].
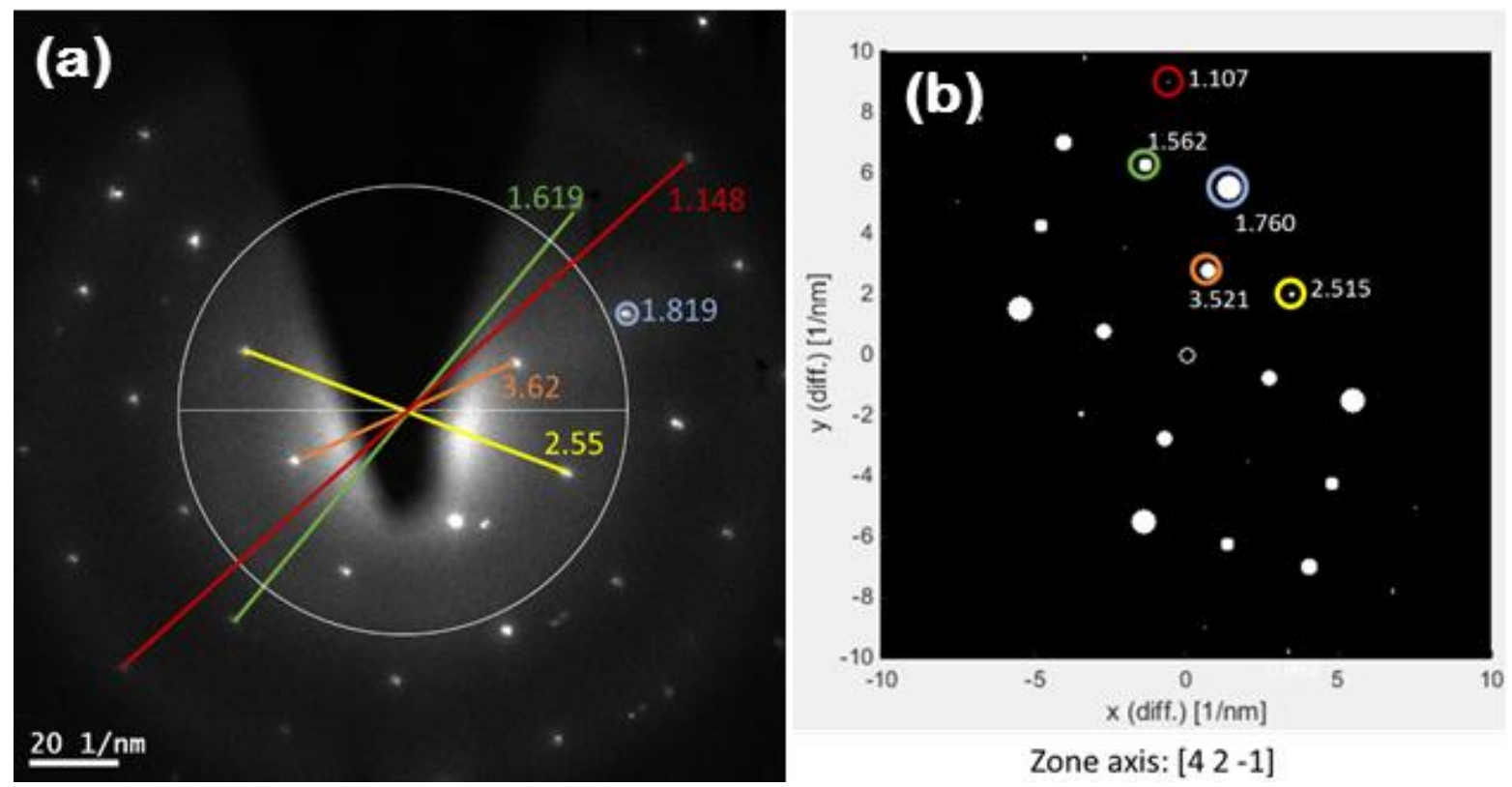

Fig. 3 - (a) SAED pattern of a single $\alpha-\mathrm{AlF}_{3}$ particle showing the spacings of five crystallographic planes and (b) simulated diffraction pattern showing a match with the experimental pattern for the zone axis [4 $2 \overline{1}]$.

The X-ray diffractogram of the as-prepared $\mathrm{C}-\mathrm{AlF}_{3}$ powder is presented in Fig. 4a. The dominant diffraction peak at $2 \theta \sim 25.25^{\circ}$ clearly corresponds to the (012) reflection of the $\alpha-\mathrm{AlF}_{3}$ rhombohedral crystal phase, while additional but less intense peaks arising at $\sim 42.59^{\circ}, \sim 51.85^{\circ}, \sim 58.07^{\circ}$ and $59.06^{\circ}$ also seem to describe $\alpha-\mathrm{AlF}_{3}$ reflections, in close agreement with the Joint Committee on Powder Diffraction Standards (JCPDS card no. 43-0435). This is also in agreement with the aforementioned SAED analysis as well as the primary observations for $\mathrm{AlF}_{3}$ particle composition derived by the EDX analysis (see sections 3.1 and 3.2). Minor traces of metallic $\mathrm{Al}$ and $\mathrm{Al}_{2} \mathrm{O}_{3}$ were also detected as remnants of the combustion synthesis procedure. In any case, the available carbon fraction cannot be observed by XRD due to its amorphous nature, as observed by TEM (see section 3.1), and therefore micro-Raman spectroscopy was employed for this purpose. Carbon-based structures, such as 
functionalized graphene and graphene oxide materials [39-41], carbon nanotubes [42] as well as carbon foams [43-45], are routinely characterized for their structure using Raman spectroscopy. The microRaman spectrum recorded for the as-prepared $\mathrm{C}-\mathrm{AlF}_{3}$ composite is shown in Fig. 4b. Two very broad asymmetric bands are observed at Raman frequencies of 1365 and $1600 \mathrm{~cm}^{-1}$, which correspond to the defect activated $\mathrm{D}$ band arising from the breathing vibrations of carbon atoms with $\mathrm{sp}^{3}$ hybridization and the graphitic $\mathrm{G}$ band due to the bond stretching of $\mathrm{sp}^{2}$ carbon atoms in a two-dimensional hexagonal lattice, respectively. The spectrum at high frequency shows a very broad feature, which could be fitted with two very broad bands as well, at the frequencies of 2715 and $3010 \mathrm{~cm}^{-1}$, corresponding to the $2 \mathrm{D}$ and $\mathrm{D}+\mathrm{G}$ Raman overtones, respectively. The integrated intensity ratio of the $\mathrm{D}$ to $\mathrm{G}$ bands $\left(A_{D} / A_{G}\right)$ is equal to 1.65 and the respective peak intensity ratio $\left(I_{D} / I_{G}\right)$ is given as 0.77 . These high ratios are indicative of extensive disorder in the structure, which corroborates the lacking graphitic peaks in the XRD patterns. Raman spectroscopy studies on carbon foam materials generally show the peaks of the D and G bands at about 1355 and $1588 \mathrm{~cm}^{-1}$, respectively $[43,44]$ (see marked vertical lines in Fig. 4b. In the case of the $\mathrm{C}-\mathrm{AlF}_{3}$ composite, the two bands are positively shifted and the $\mathrm{G}$ band peak reaches the frequency of $1600 \mathrm{~cm}^{-1}$. The above observations in combination with the shape and width of the Raman bands indicate that the carbon foam structure is in stage 2 of the amorphization, which denotes the path from the nanocrystalline graphite to amorphous graphite according to Ferrari's classification [46], in the region where significant $\mathrm{sp}^{2}$-bonded rings still remain in the structure. There, the $I_{D} / I_{G}$ ratio is proportional to $L_{a}^{2}$ in accordance to the semi-empirical equation $I_{D} / I_{G}=C \cdot L^{2}$, where $L_{a}$ is the in-plane graphitic correlation length and $C$ is a constant equal to $0.0055 \AA^{-2}$ under $514 \mathrm{~nm}$ excitation [46]. In this case, the equivalent $L_{a}$ value was estimated at around $1.7 \mathrm{~nm}$. In order to fully match the observed $I_{D} / I_{G}$ ratios with the positive shifts of the Raman bands in 
the Ferrari correlation graphs, significant compressive strain of the materials also has to be accounted for [47].
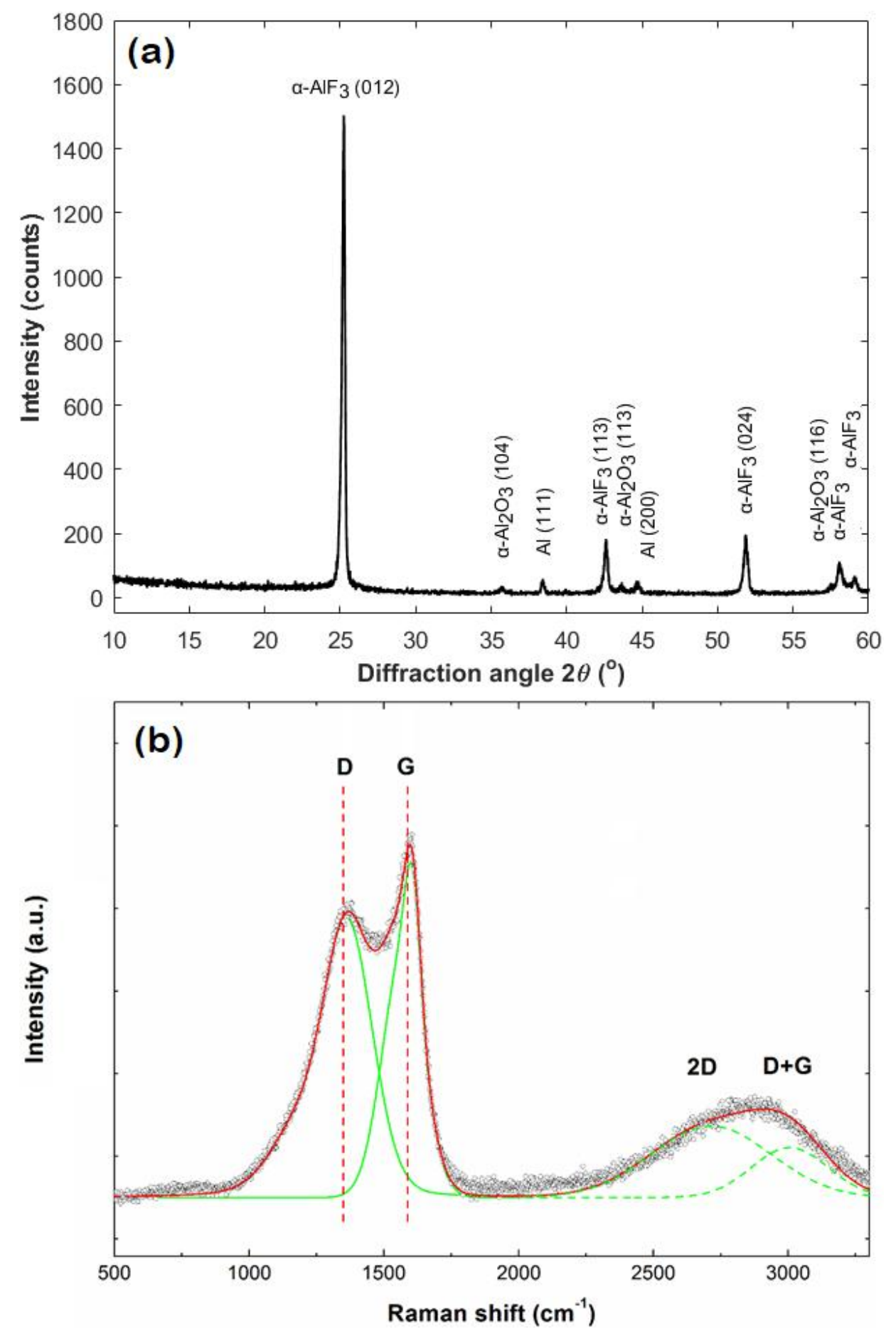
Fig. 4 - (a) X-ray diffractogram and (b) micro-Raman spectrum of the as-prepared C-AlF ${ }_{3}$ composite; red and green spectra lines are fitting curves and spectral fitting components, respectively; vertical dashed lines mark the standard position of the D band $\left(1355 \mathrm{~cm}^{-1}\right)$ and the $\mathrm{G}$ band $\left(1588 \mathrm{~cm}^{-1}\right)[43,44]$.

\subsection{Porosity and related properties}

The $\mathrm{N}_{2}$ adsorption/desorption isotherm recorded at $77 \mathrm{~K}$ is shown in Fig. 5a. The degassed $\mathrm{C}-\mathrm{AlF}_{3}$ composite demonstrates a type IV isotherm, as classified by the International Union of Pure and Applied Chemistry (IUPAC), which is characteristic of mesoporous materials (i.e. pore widths between 2 and 50 $\mathrm{nm}$ ) [48]. The formation of a visible hysteresis loop between the adsorption and desorption curves at higher relative pressures $\left(P / P_{0}>0.5\right)$ can be attributed to capillary condensation of $\mathrm{N}_{2}$ gas within the mesopores. The shape of the loop is classified as an H3 type based on IUPAC [48]. However the desorption closing point is not connected with cavitation effects, which give a sharp step-down of the desorption branch at $P / P_{0} \sim 0.4$ for $\mathrm{N}_{2}$ at $77 \mathrm{~K}$. Loops of this type are given by pore networks consisting of macropores (i.e. pores with widths greater than $50 \mathrm{~nm}$ ) which are not completely filled with pore condensate. The fact that no point of saturation is reached up to the $P / P_{0}$ value of $\sim 0.99$ with the adsorption isotherm rising indefinitely in a vertical path is most likely attributed to $\mathrm{N}_{2}$ condensation in macropores and/or multi-layer formation on the powder's external rough surface [34]. The specific area of the degassed $\mathrm{C}-\mathrm{AlF}_{3}$ composite was estimated at $50 \mathrm{~m}^{2} / \mathrm{g}$ using the multi-point BET method (Fig. S5a), while for comparison the equivalent value given by the QSDFT method was almost the same (i.e. $52 \mathrm{~m}^{2} / \mathrm{g}$ ). A t-plot analysis of the data (see Fig. S5b) revealed the existence of quite limited microporosity (i.e. pore widths below $2 \mathrm{~nm}$ ), with a micropore volume of $0.013 \mathrm{~cm}^{3} / \mathrm{g}$ and a micropore specific area of around $30 \mathrm{~m}^{2} / \mathrm{g}$ (representing $60 \%$ of the total specific area). The PSD analysis on the basis of the QSDFT method (Fig. 5b) revealed that the existing pores across the surface should exhibit three size distribution maxima at $\sim 1.2, \sim 8.5$ and $\sim 14.5 \mathrm{~nm}$, while the cumulative pore volume was 
roughly estimated around $0.13 \mathrm{~cm}^{3} / \mathrm{g}$ for pores with widths less than $50 \mathrm{~nm}$ (see inset Fig. $5 \mathrm{~b}$ ). Based on the above, it seems that the as-prepared $\mathrm{C}-\mathrm{AlF}_{3}$ powder combines contributions of micro-, meso- and macro-porosity as well as external surface, in agreement with the SEM and TEM observations (see section 3.1). 
(a)

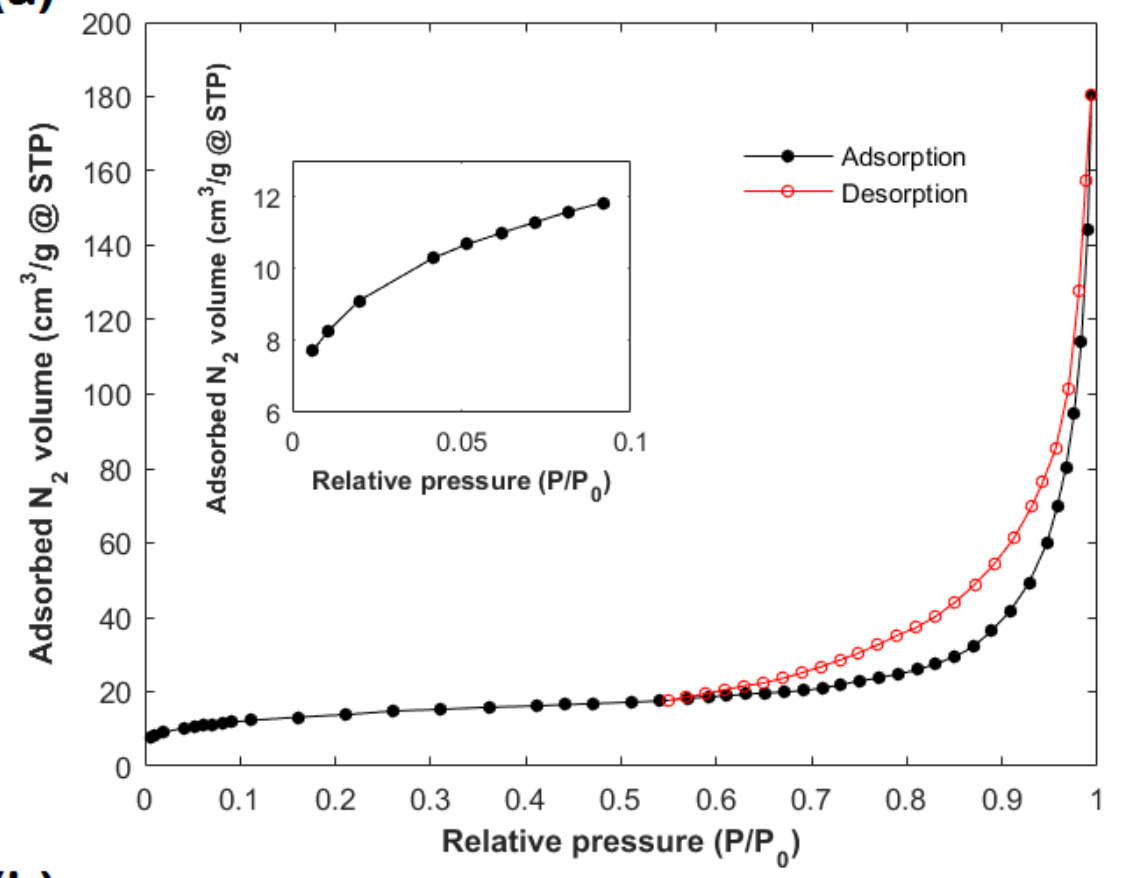

(b)

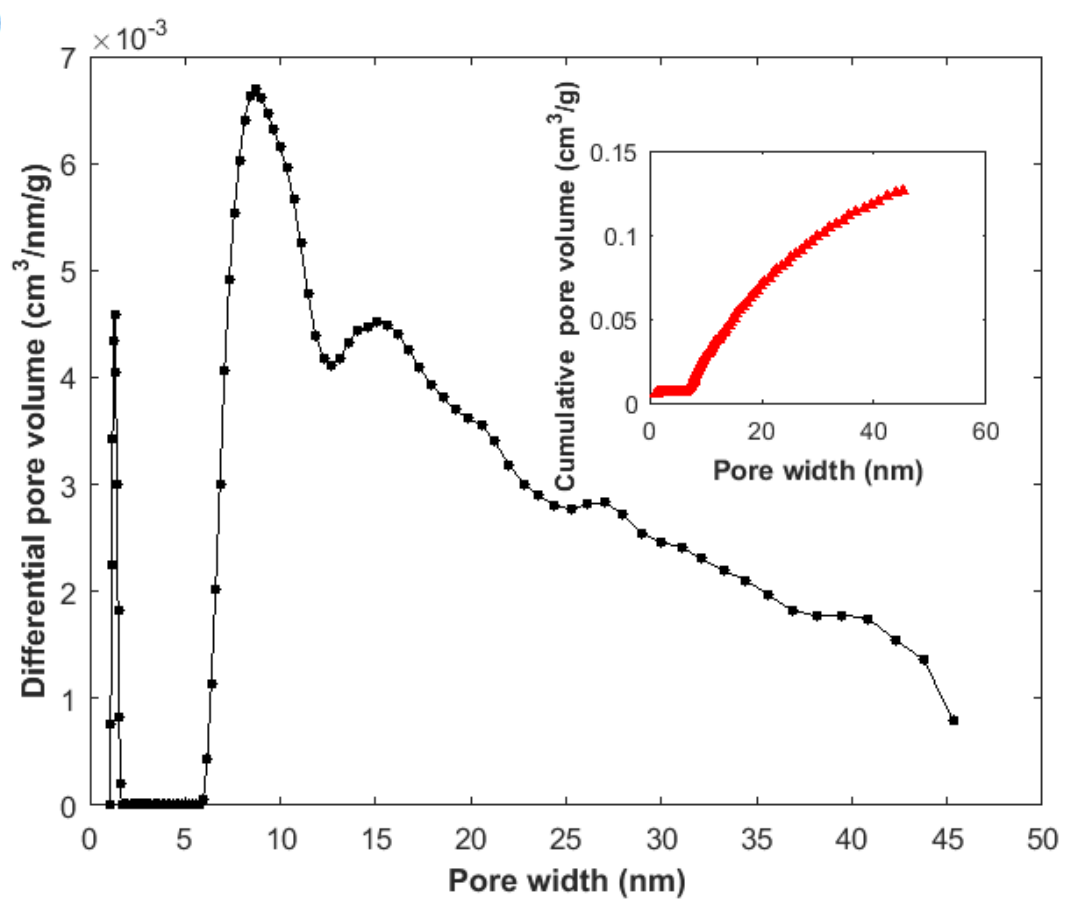

Fig. 5 - (a) $\mathrm{N}_{2}$ adsorption (full symbols) and desorption (empty symbols) isotherms recorded at $77 \mathrm{~K}$ for the degassed $\mathrm{C}-\mathrm{AlF}_{3}$ powder; the inset shows the adsorption behavior at $\mathrm{P} / \mathrm{P}_{0}<0.1$ and (b) differential and cumulative (inset) pore size distribution analysis of the degassed C-AlF3 composite material using the QSDFT method for slit/cylinder-like shape pores in the $\mathrm{N}_{2}$ desorption data. 


\subsection{Potential applications and future work}

As briefly mentioned in the introduction, $\mathrm{AlF}_{3}$ can be effectively used in the field of electrochemical energy storage and more specifically in the technology of $\mathrm{Li}$-ion batteries. In this respect, $\mathrm{AlF}_{3}$ can act as a promising cathode material [18], enhance the performance of graphite anodes [19] as well as improve the electrochemical cycling of Li-enriched nickel- manganese oxide electrodes [20]. Moreover, a coating layer of $\mathrm{AlF}_{3}$ is proven to be very effective in suppressing the gas generation and swelling behavior of spinel $\mathrm{Li}_{4} \mathrm{Ti}_{5} \mathrm{O}_{12}$ (LTO) anodes in Li-ion batteries, thus allowing the improvement of their high-rate charge/discharge performance [21]. The carbon-based nature of the herein presented $\mathrm{C}-\mathrm{AlF}_{3}$ powder could allow the facile development of such functional components (e.g. electrodes, thin films or coatings) for the aforementioned applications by using binders, pressing or spark plasma sintering methods. Further research is necessary to control the size and dispersion of the $\mathrm{AlF}_{3}$ nanoparticles within the porous network and to increase the available specific area of the carbonaceous foam by varying the initial Al particle size, mass fraction of Al/THV and combustion conditions. These can help overcome the limitations of the method, such as the cost and safety hazards of Al nanoparticles, while minimizing the release of gaseous HF from the reactions.

\section{Conclusions}

The current work demonstrates that carbon foam-aluminum fluoride $\left(\mathrm{C}-\mathrm{AlF}_{3}\right)$ nanocomposite materials can be produced by employing a few-step and rapid combustion synthesis approach as an appealing alternative to well-established wet chemical procedures. Upon flame ignition and combustion of a solid-state mixture of THV fluoropolymer and nano-sized Al powder, a carbon foam-like porous structure doped with cubic- and/or cuboid-like $\mathrm{AlF}_{3}$ nano-sized particles (i.e. from 100 up to $500 \mathrm{~nm}$; $\sim 240 \mathrm{~nm}$ in average) forms due to condensation of the sublimating $\mathrm{AlF}_{3}$. These embedded nanoparticles exhibit a rhombohedral $\alpha-\mathrm{AlF}_{3}$ crystal structure, the foamy matrix displays features of 
disordered carbon-based materials, while the $\mathrm{C}_{-} \mathrm{AlF}_{3}$ composite in total shows a combination of micro-, meso- and macro-porous characteristics with an available specific area of $\sim 50 \mathrm{~m}^{2} / \mathrm{g}$. The combustion synthesis method could have a significant impact on the design and development of composite material systems (e.g. carbon-metal, carbon-metal fluoride, etc.), while the structural optimization of the herein presented $\mathrm{C}-\mathrm{AlF}_{3}$ nanocomposite can potentially allow its usage in green energy-related applications such as electrochemical energy storage.

\section{Acknowledgments}

AGK acknowledges funding from EU [FP7/2007-2013] under grant agreement 316494 (DESTINY) project. EB is supported by a Natural Sciences and Engineering Research Council of Canada PostDoctoral Fellowship grant. The TEM part of the study was supported by the Young Investigator Program of Department of Defense Office of Naval Research (Grant Number: 108305). The authors are grateful to Christos Tampaxis from NCSR Demokritos (Athens, Greece), for collecting the $\mathrm{N}_{2}$ sorption data presented in this work.

\section{Supplementary information associated with this article can be found in the online version.}

\section{References}

[1] B. Bayatsarmadi, Y. Zheng, A. Vasileff, S. Z Qiao, Recent advances in atomic metal doping of carbon-based nanomaterials for energy conversion, Small (2017) 1700191.

[2] L. He, F. Weniger, H. Neumann, M. Beller, Synthesis, characterization, and application of metal nanoparticles supported on nitrogen-doped carbon: Catalysis beyond electrochemistry, Angew. Chem. Int. Ed. 55 (2016) 12582-94. 
[3] E. Pérez-Mayoral, V. Calvino-Casilda, E. Soriano, Metal-supported carbon-based materials: opportunities and challenges in the synthesis of valuable products, Catal. Sci. Tech. 6 (2016) 1265-91.

[4] R.J. White, R. Luque, V.L. Budarin, J.H. Clark, D.J. Macquarrie, Supported metal nanoparticles on porous materials. Methods and applications, Chem. Soc. Rev. 38 (2009) 481-94.

[5] J. Shin, K.Y. Lee, T. Yeo, W. Choi, Facile one-pot transformation of iron oxides from $\mathrm{Fe}_{2} \mathrm{O}_{3}$ nanoparticles to nanostructured $\mathrm{Fe}_{3} \mathrm{O}_{4} @ \mathrm{C}$ core-shell composites via combustion waves, Sci. Rep. 6 (2016): 21792.

[6] J. Zhang, X. Liu, G. Neri, N. Pinna. Nanostructured materials for room- temperature gas sensors, Adv. Mater. 28 (2016) 795-831.

[7] F. Li, L. Chen, G.P. Knowles, D.R. MacFarlane, J. Zhang, Hierarchical mesoporous $\mathrm{SnO}_{2}$ nanosheets on carbon cloth: a robust and flexible electrocatalyst for $\mathrm{CO}_{2}$ reduction with high efficiency and selectivity, Angew. Chem. Int. Ed. 56 (2017) 505-9.

[8] G.M. Psofogiannakis, T.A. Steriotis, A.B. Bourlinos, E.P. Kouvelos, G.C. Charalambopoulou, A.K. Stubos, et al., Enhanced hydrogen storage by spillover on metal-doped carbon foam: An experimental and computational study, Nanoscale 3 (2011) 933-6.

[9] J. Shin, D. Shin, H. Hwang, T. Yeo, S. Park, W. Choi, One-step transformation of $\mathrm{MnO}_{2}$ into $\mathrm{MnO}_{2-\mathrm{x}} @$ carbon nanostructures for high-performance supercapacitors using structureguided combustion waves, J. Mater. Chem A 5 (2017) 13488-98.

[10] T. Minović-Arsić, A. Kalijadis, B. Matović, M. Stoiljković, J. Pantić, J. Jovanović, et al., Arsenic (III) adsorption from aqueous solutions on novel carbon cryogel/ceria nanocomposite, Process. Appl. Ceram. 10 (2016) 17-23. 
[11] Y. Liu, C. Nie, X. Liu, X. Xu, Z. Sun, L. Pan, Review on carbon-based composite materials for capacitive deionization, RSC Adv. 5 (2015) 15205-25.

[12] L.E. Aneke, L.A. Gerritsen, P.J. Van den Berg, W.A. De Jong, The disproportionation of toluene over a HY/ $\beta-A l F 3 / C u$ catalyst: 1. Preparation and characterization, J. Catal. 59 (1979) 26-36.

[13] J.R. Kaiser, L.D. Moore, R.C. Odioso, Skeletal isomerization of olefins over aluminum fluoride catalysts, Ind. Eng. Chem. Prod. Res. Dev. 1 (1962) 127-32.

[14] S. Kolås, T. Støre, Bath temperature and $\mathrm{AlF}_{3}$ control of an aluminium electrolysis cell, Control Eng. Pract. 17 (2009) 1035-43.

[15] A. Sterten, P. Solli, An electrochemical current efficiency model for aluminium electrolysis cells, J. Appl. Electrochem. 26 (1996) 187-93.

[16] C. Benhamideche, A. Boutarfaia, M. Poulain, Fluoroaluminate glasses, J. Alloy. Comp. 366 (2004) 233-40.

[17] D.F. Ehrt, Luoroaluminate glasses for lasers and amplifiers, Curr. Opin. Solid State Mater. Sci. 7 (2003) 135-41.

[18] N. Owen, Q. Zhang, Investigations of aluminum fluoride as a new cathode material for lithiumion batteries, J. Appl. Electrochem. 47 (2017) 417-31.

[19] F. Ding, W. Xu, D. Choi, W. Wang, X. Li, M.H. Engelhard, et al., Enhanced performance of graphite anode materials by $\mathrm{AlF}_{3}$ coating for lithium-ion batteries, J. Mater. Chem. 22 (2012) $12745-51$.

[20] Y.K. Sun, M.J. Lee, C.S. Yoon, J. Hassoun, K. Amine, B. Scrosati, The role of $\mathrm{AlF}_{3}$ coatings in improving electrochemical cycling of $\mathrm{Li}$-enriched nickel- manganese oxide electrodes for $\mathrm{Li}$ ion batteries, Adv. Mater. 24 (2012) 1192-6. 
[21] W. Li, X. Li, M. Chen, Z. Xie, J. Zhang, S. Dong, M. Qu, AlF 3 modification to suppress the gas generation of $\mathrm{Li}_{4} \mathrm{Ti}_{5} \mathrm{O}_{12}$ anode battery. Electrochim. Acta 139 (2014) 104-110.

[22] E. Kemnitz, Nanoscale metal fluorides: A new class of heterogeneous catalysts, Catal. Sci. Technol. 5 (2015) 786-806.

[23] M. Inagaki, J. Qiu, Q. Guo, Carbon foam: Preparation and application, Carbon 87 (2015) 12852.

[24] Y. Zhang, Y. Huang, H. Chen, Z. Huang, Y. Yang, P. Xiao, et al., Composition and structure control of ultralight graphene foam for high-performance microwave absorption, Carbon 105 (2016) 438-47.

[25] Z. Li, X. Hu, D. Xiong, B. Li, H. Wang, Q. Li, Facile synthesis of bicontinuous microporous/mesoporous carbon foam with ultrahigh specific surface area for supercapacitor application, Electrochim. Acta 219 (2016) 339-49.

[26] M. Letellier, A. Szczurek, M.-C. Basso, A. Pizzi, V. Fierro, O. Ferry, A. Celzard Preparation and structural characterisation of model cellular vitreous carbon foams, Carbon 112 (2017) 208-18.

[27] R.A. Yetter, G.A. Risha, S.F. Son, Metal Particle Combustion and Nanotechnology. Proc. Combust. Inst. 2009, 32 II (2), 1819-38.

[28] S.C. Stacy, M.L. Pantoya, Laser ignition of nano-composite energetic loose powders, Propellants, Explos. Pyrotech. 38 (2013) 441-7.

[29] A. Peretz, Some theoretical considerations of metal fluorocarbon compositions for ramjet fuels, $8^{\text {th }}$ Int. Symp. Air Breath. Engines (1987) 398-403. 
[30] M.A. Rubio, I.E. Gunduz, L.J. Groven, T.R. Sippel, C.W. Han, R.R. Unocic, et al., Microexplosions and Ignition Dynamics in Engineered Aluminum/polymer Fuel Particles, Combust. Flame 176 (2017) 162-71.

[31] M. Klinger, A Jäger, Crystallographic Tool Box (CrysTBox): Automated tools for transmission electron microscopists and crystallographers, J. Appl. Crystallogr. 48 (2015) 2012-8.

[32] K. Falconer, Fractal geometry: Mathematical foundations and applications. John Wiley \& Sons; 1990. p. 38-47.

[33] International Standard Organization, Determination of the specific surface area of solids by gas adsorption - BET method, ISO 9277:2010(E), $2^{\text {nd }}$ edition, 2010.

[34] J. Rouquerol, F. Rouquerol, P. Llewellyn, G. Maurin, K.S. Sing, Adsorption by powders and porous solids: principles, methodology and applications, Academic Press, 2013.

[35] A.V. Neimark, Y. Lin, P.I. Ravikovitch, M. Thommes, Quenched solid density functional theory and pore size analysis of micro-mesoporous carbons, Carbon 47 (2009) 1617-1628.

[36] M. Reuter, P. Franz, E. Wolter, Fraktaldimension von grauwertbildern, Studienarbeit. Universitat Hannover, 1999.

[37] B. Mandelbrot, The fractal geometry of nature, W.H. Freeman \& Co, New York, 1983.

[38] R. König, G. Scholz, K. Scheurell, D. Heidemann, I. Buchem, W.E.S. Unger, et al., Spectroscopic characterization of crystalline $\mathrm{AlF}_{3}$ phases, J. Fluor. Chem. 131 (2010) 91-7.

[39] V. Georgakilas, M. Otyepka, A.B. Bourlinos, V. Chandra, N. Kim, K.C. Kemp, et al., Functionalization of graphene: covalent and non-covalent approaches, derivatives and applications, Chem. Rev. 112 (2012) 6156-6214.

[40] N. Kostoglou, V. Tzitzios, A.G. Kontos, K. Giannakopoulos, C. Tampaxis, A. Papavasiliou, et al., Synthesis of nanoporous graphene oxide adsorbents by freeze-drying or microwave 
radiation: Characterization and hydrogen storage properties, Int. J. Hydrogen Energy 40 (2015) 6844-52.

[41] G. Pilatos, M. Samouhos, P. Angelopoulos, M. Taxiarchou, Ch. Veziri, R. Hutcheon, et al., Carbon nanotubes growth on expanded perlite particles via CVD method: The influence of the substrate morphology, Chem. Eng. J. 291 (2016) 106-14.

[42] M.S. Dresselhaus, G. Dresselhaus, R. Saito, A. Jorio, Raman spectroscopy of carbon nanotubes, Phys. Rep. 409 (2005) 47-99.

[43] E. Munoz, M.L. Ruiz-Gonzalez, A. Seral-Ascaso, M.L. Sanjuan, J.M. Gonzalez-Calbet, M. Laguna, et al., Tailored production of nanostructured metal/carbon foam by laser ablation of selected organometallic precursors, Carbon 48 (2010) 1807-14.

[44] F. Zhang, T. Liu, G. Hou, T. Kou, L. Yue, R. Guan, et al., Hierarchically porous carbon foams for electric double layer capacitors, Nano Res. 9 (2016) 2875-88.

[45] A. Seral-Ascaso, R. Garriga, M. Luisa Sanjuán, J.M. Razal, R. Lahoz, M. Laguna, et al., 'Laser chemistry' synthesis, physicochemical properties, and chemical processing of nanostructured carbon foams, Nanoscale Res. Lett. 8 (2013) 233.

[46] A.C. Ferrari, J. Robertson, Interpretation of Raman spectra of disordered and amorphous carbon, Phys. Rev. B 61 (2000) 14095-107.

[47] R. Krishna, A.N. Jones, R. Edge, B.J. Marsden, Residual stress measurements in polycrystalline graphite with micro-Raman spectroscopy, Radiat. Phys. Chem. 111 (2015) 14-23.

[48] M. Thommes, K. Kaneko, A.V. Neimark, J.P. Olivier, F. Rodriguez-Reinoso, J. Rouquerol, et al., Physisorption of gases, with special reference to the evaluation of surface area and pore size distribution (IUPAC Technical Report), Pure Appl. Chem. 87 (2015) 1051-69. 


\section{Supplementary Material}

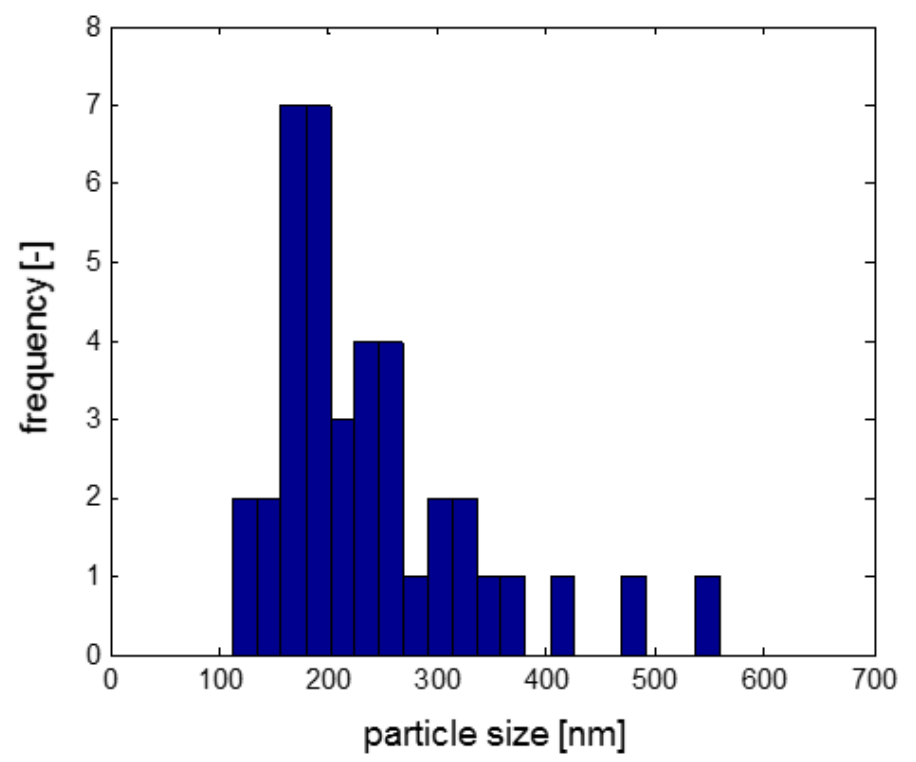

Fig. S1 - Particle size distribution histogram derived from a statistical analysis of 39 cubic nano-sized crystals from three different SEM images. The minimum and maximum particle sizes correspond to 100 and $550 \mathrm{~nm}$, respectively, the average particle size is $240 \mathrm{~nm}$, while the standard deviation is $96 \mathrm{~nm}$. 


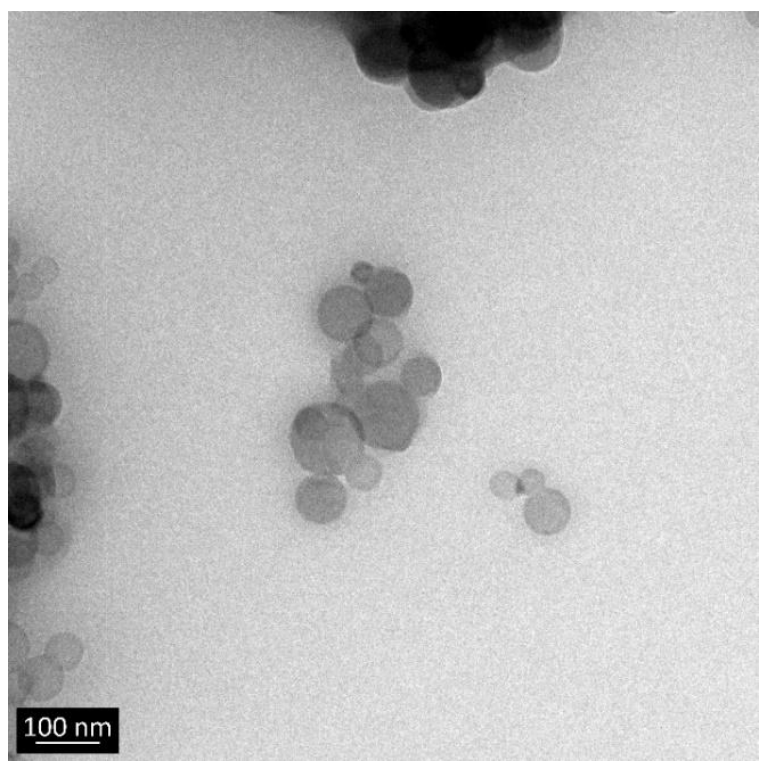

Fig. S2 - High-magnification TEM image of the solid THV-nAl mixture dissolved in acetone and dried onto $\mathrm{Cu}$ grids. The clusters of $\mathrm{Al}$ nanoparticles are dispersed within the THV polymer matrix. The overall mass percent within the image is similar to the overall composition of the bulk composite.
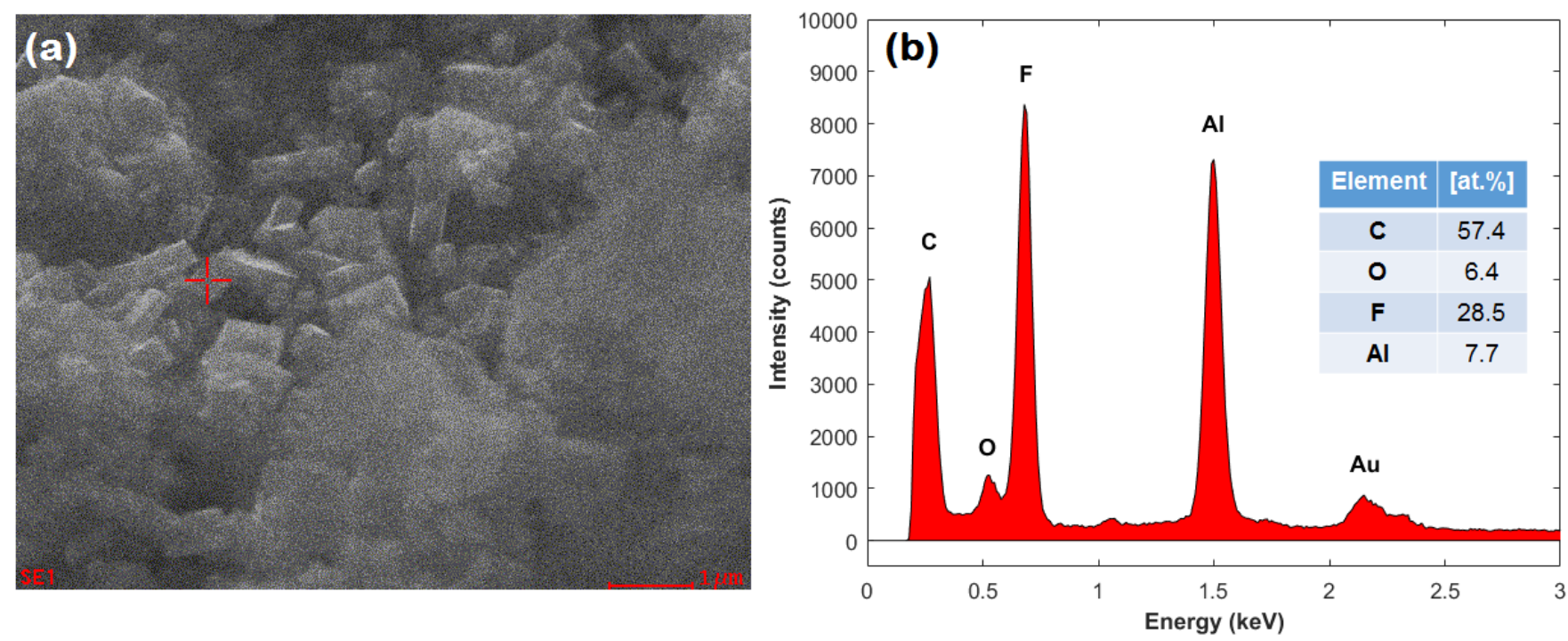

Fig. S3 - (a) High-magnification SEM image showing the surface region investigated by EDX and (b) the respective EDX spectrum of the $\mathrm{C}-\mathrm{AlF}_{3}$ composite material; the inset table shows the atomic percentages of the detected elements $(\mathrm{C}, \mathrm{O}, \mathrm{F}$ and $\mathrm{Al})$ excluding $\mathrm{Au}$, which refers to the sputter-coating material used for improved conductivity for the SEM/EDX studies. 

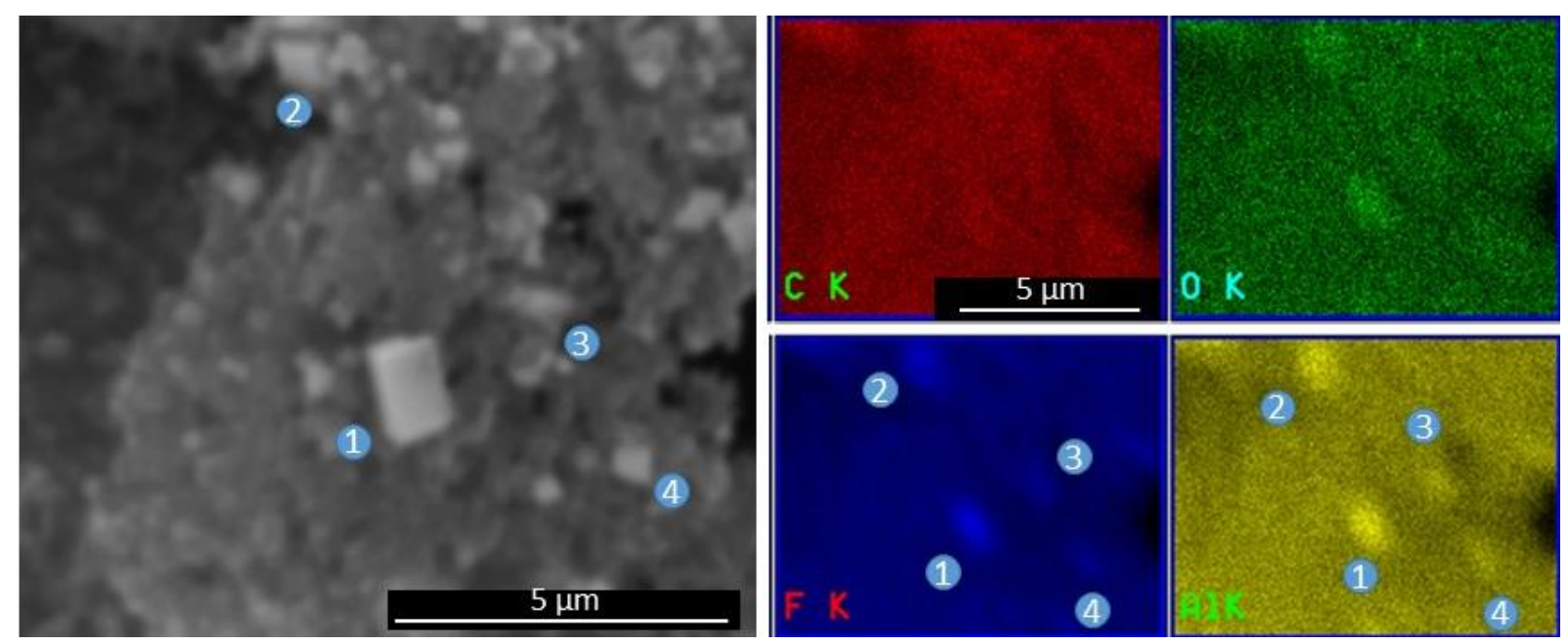

Fig. S4 - Elemental mapping of the $\mathrm{C}_{-} \mathrm{AlF}_{3}$ microstructure using combined SEM/EDX. Left: SEM image with numbered regions ( 1 to 4 ) indicating nano-sized cubic $\mathrm{AlF}_{3}$ crystals embedded within the surface; Right: corresponding elemental maps $(\mathrm{C}, \mathrm{O}, \mathrm{F}$ and $\mathrm{Al})$ using EDX. 

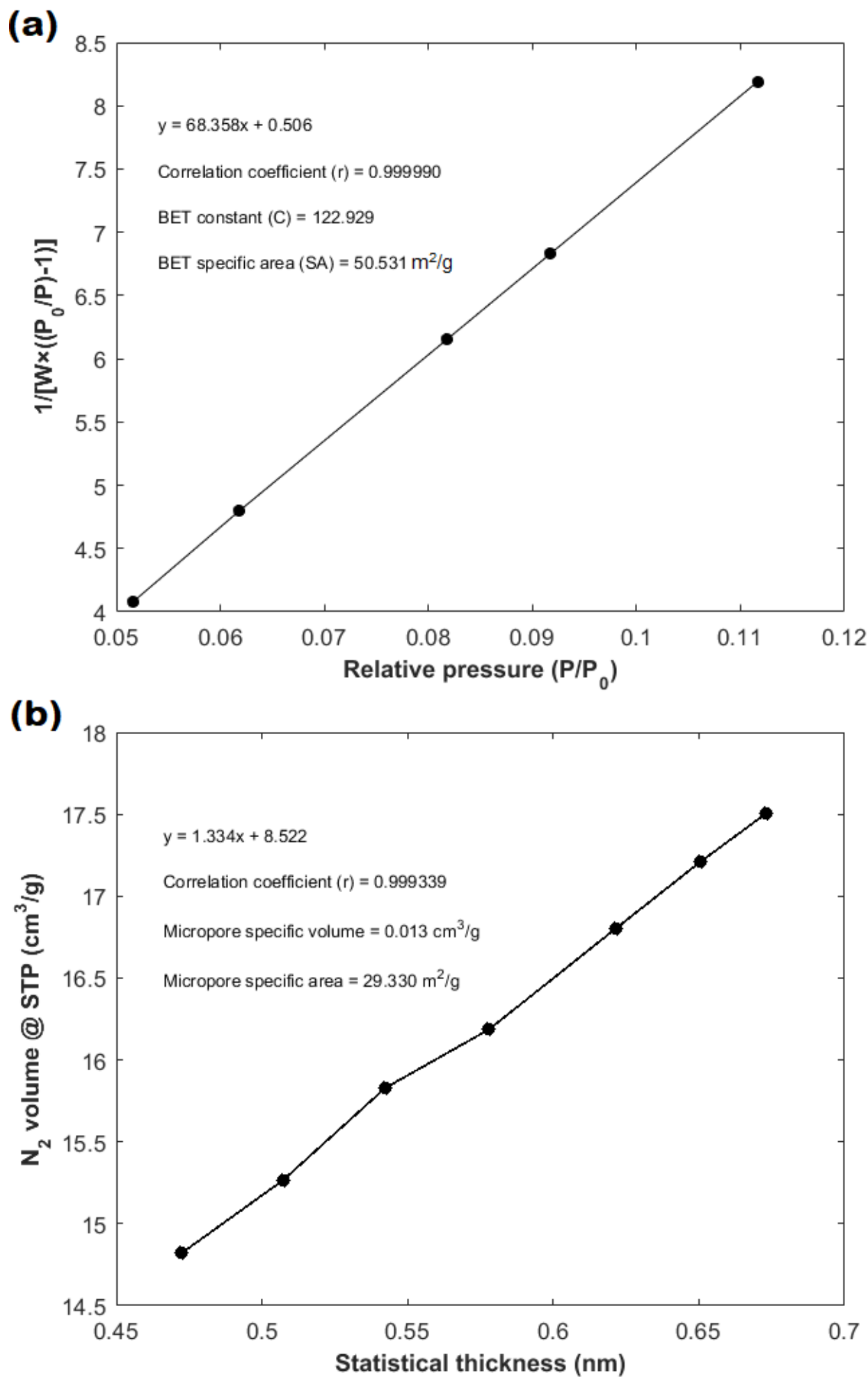

Fig. S5 - (a) Multi-point BET plot and (b) Carbon Black t-plot of the degassed $\mathrm{C}_{-} \mathrm{AlF}_{3}$ sample showing a correlation coefficient of close-to-unity $(\mathrm{r} \sim 1)$. 